\title{
Anxiety and depression among dairy farmers: the impact of COPD
}

This article was published in the following Dove Press journal:

International Journal of COPD

\author{
Alicia Guillien' \\ Lucie Laurent ${ }^{2}$ \\ Thibaud Soumagne ${ }^{3}$ \\ Marc Puyraveau ${ }^{4}$ \\ Jean-Jacques Laplante ${ }^{5}$ \\ Pascal Andujar ${ }^{6}$ \\ Isabella Annesi-Maesano ${ }^{7}$ \\ Nicolas Roche 8,9 \\ Bruno Deganol,* \\ Jean-Charles Dalphin ${ }^{3, *}$
}

'Research Unit EA 3920, FrancheComté University, Besançon, France;

${ }^{2}$ Department of Clinical Physiology,

University Hospital, Besançon, France;

${ }^{3}$ Department of Respiratory Diseases,

University Hospital, Besançon,

France; ${ }^{4}$ Clinical Methodology

Center, University Hospital,

Besançon, France; ${ }^{5}$ Department of

Occupational Diseases, Mutualité

sociale agricole, Besançon, France;

${ }^{6}$ University of Medical Sciences,

Paris-est Créteil University, Créteil,

France; ${ }^{7}$ Epidemiology of Allergic and Respiratory Diseases Department (EPAR), Saint-Antoine Medical School, Paris, France; ${ }^{8}$ Respiratory and Intensive Care Medicine, Cochin Hospital (AP-HP), University Paris Descartes, Paris, France; ${ }^{9}$ Research Unit EA 25 II, University Paris

Descartes, Paris, France

*These authors contributed equally to this work

Correspondence: Bruno Degano $\mathrm{CHU}$ Jean Minjoz, 3 Boulevard Fleming, 25000 Besançon, France

$\mathrm{Tel}+3338$ I2। 1807

Fax +33381668532

Email bdegano@univ-fcomte.fr
Background: Chronic obstructive pulmonary disease (COPD) and farming are two conditions that have been associated with an increased risk of anxiety and depression. Dairy farming is an independent risk factor for COPD.

Objective: To test the hypotheses that the prevalence of anxiety and/or depression is higher in dairy farmers with COPD than in farmers without COPD, and higher in dairy farmers with COPD than in non-farmers with COPD.

Methods: Anxiety and depression were evaluated using the Hospital Anxiety and Depression Scale in 100 dairy farmers with COPD (DF-COPD), 98 dairy farmers without COPD (DF-controls), 85 non-farming patients with COPD (NF-COPD) and 89 non-farming subjects without COPD (NF-controls), all identified by screening in the Franche-Comté region of France. Anxiety and depression were considered present when the Hospital Anxiety and Depression Scale score was $\geq 8$. COPD was defined by a post-bronchodilator forced expiratory volume in $1 \mathrm{~second} /$ forced vital capacity ratio $<0.7$.

Results: The crude prevalence of anxiety did not differ between the four groups, ranging from $36 \%$ in NF-controls to $47 \%$ in NF-COPD ( $p=0.15$ between groups). Similarly, the prevalence of depression did not differ significantly between the four groups ( $p=0.16$ between groups). In dairy farmers $(n=198)$, the only factors associated with anxiety were quality of life and current smoking. Depression in dairy farmers was associated with airflow limitation (lower forced expiratory volume in 1 second and COPD grade 2 or more) as well as with some COPD-related features (dyspnea severity, current smoking, and poorer quality of life). In non-farmers, both anxiety and depression were associated with airflow limitation and COPD-related features.

Conclusion: In our population, the prevalence of anxiety and/or depression was similar in dairy farmers with and without COPD and in non-farmers with COPD. Nevertheless, the degree of airway obstruction and some COPD-related features were associated with depression among dairy farmers, whereas these factors were not associated with anxiety.

Keywords: COPD, farmers, forced expiratory volume in 1 second, Hospital Anxiety and Depression Scale, St George's Respiratory Questionnaire

\section{Introduction}

Chronic obstructive pulmonary disease (COPD) is currently the most common respiratory disease, affecting between $5 \%$ and $10 \%$ of subjects over 40 years of age. ${ }^{1}$ This disease leads to a deterioration of the patient's quality of life $^{2,3}$ and involves considerable costs due to health care, professional absenteeism and morbidity-mortality. ${ }^{4}$ COPD primarily affects the lungs, but also has consequences on other organs and functions..$^{5}$ Anxiety and depression are among the most frequent comorbidities identified in COPD patients. ${ }^{6-8}$ The causal relationships between COPD and anxiety and/or depression are multifaceted. ${ }^{9,10}$ Patients with COPD are submit your manuscript Dovepress f
International Journal of COPD 2018:|3 |-9

(c) (i) (8) 2018 Guillien et al. This work is published and licensed by Dove Medical Press Limited. The full terms of this license are avaliable at https://www.dovepress.com/terms.php C. hereby accept the Terms. Non-commercial uses of the work are permitted without any further permission from Dove Medical Press Limited, provided the work is properly attributed. For permission for commercial use of this work, please see paragraphs 4.2 and 5 of our Terms (https://www.dovepress.com/terms.php). 
more likely to develop anxiety and/or depression than control subjects, while COPD patients with anxiety and/or depression have a higher risk of COPD-related mortality than COPD patients without anxiety and/or depression. ${ }^{10,11}$

Although the main causal risk factor for COPD in developed countries is tobacco smoking, COPD is also attributable to environmental and/or professional exposures. ${ }^{12,13} \mathrm{COPD}$ in dairy farmers is, in this regard, a typical example of COPD attributable to exposure to organic dusts at work. ${ }^{14} \mathrm{~A}$ recent study showed that COPD prevalence among farmers is approximately twice as high as in subjects with no occupational exposure. ${ }^{15}$ Many studies have shown that farming may be associated with an increased risk of anxiety and depression. ${ }^{16-19}$ This could partly be explained by the fact that in some cases, farmers are daily subjected to multiple stress factors such as economic circumstances, weather conditions, labor problems and social conditions. ${ }^{16,19,20}$ Nevertheless, the prevalence of anxiety and depression among farmers with COPD is currently unknown.

Given that COPD and dairy farming may both be risk factors for anxiety and/or depression, we aimed to test the hypothesis that a higher prevalence of anxiety and/or depression exists in farmers with COPD than in farmers without COPD, together with a higher prevalence of anxiety and/or depression in farmers with COPD than in non-farmers with COPD. We also aimed to study the relationship between anxiety and/or depression and selected COPD-related features in farmers and in non-farmers. To achieve this aim, we assessed anxiety and depression by the self-administered Hospital Anxiety and Depression Scale (HADS) in four groups of subjects: dairy farmers with and without COPD, as well as nonfarmers with and without COPD, all identified by screening.

\section{Subjects and methods Screening programs}

Data for this study were collected as part of the BALISTIC project (COPD in dairy farmers: screening, characterization and constitution of a cohort; ClinicalTrials.gov Identifier: NCT02540408) which was conducted from 2011 to 2015 at the University Hospital of Besançon in collaboration with the French national social security system for agricultural workers (Mutualité Sociale Agricole [MSA]) and the federation of community health practices of Franche-Comté (Fédération des Maisons de Santé Comtoises). This study was set up primarily to assess the prevalence and some specific characteristics of COPD in dairy farmers (COPD secondary to organic dust exposure) in comparison with COPD in patients without any occupational exposure and with matched controls without COPD. ${ }^{21}$
COPD patients and matched controls were recruited through two parallel screening programs (screening phase of the BALISTIC study). Inclusion criteria in the screening programs were: men or women aged between 40 and 74 years, with no history of chronic respiratory disease including asthma and COPD or related conditions (chronic bronchitis, emphysema), and either being a dairy farmer (dairy farmer subgroups) or not being exposed to any occupational hazard associated with COPD (non-farmer subgroups). One of these two programs was conducted during free health checkups organized by the MSA for their affiliated members; COPD screening was proposed to all invited subjects who attended the health checkup and who fulfilled the inclusion criteria. In parallel, general practitioners of the Fédération des Maisons de Santé Comtoises conducted a second program whereby they invited all their patients who met the inclusion criteria to take part in the COPD screening program.

For screening, spirometry was performed as previously described. ${ }^{15}$ Spirometry outcomes included forced expiratory volume in 1 second $\left(\mathrm{FEV}_{1}\right)$ and forced vital capacity (FVC). A bronchodilation test was performed when the $\mathrm{FEV}_{1}$ / FVC ratio was $<0.70 .{ }^{22}$ Predicted values were based on the European Coal and Steel Community equations. ${ }^{23}$

\section{Study groups}

A diagnosis of COPD was retained when the $\mathrm{FEV}_{1} / \mathrm{FVC}$ ratio post-bronchodilator was $<0.70$. COPD patients were rated as either grade 1 ( $\mathrm{FEV}_{1}>80 \%$ of the predicted value) or grade 2 or more $\left(\mathrm{FEV}_{1} \leq 80 \%\right.$ of the predicted value). Spirometry was considered normal when the $\mathrm{FEV}_{1} / \mathrm{FVC}$ ratio was $>0.70$ and $\mathrm{FEV}_{1}$ was $>80 \%$ of the predicted value before bronchodilator administration.

During the study period, all subjects with COPD detected during the screening phase of the BALISTIC study were invited to participate in the characterization phase of the study. Those who agreed to participate in the characterization phase were included in two subgroups, namely, dairy farmers with COPD (DF-COPD) and non-farmers with COPD (NF-COPD). An equivalent number of subjects with normal spirometry (as defined above) who had participated in the screening phase of the study were frequency matched with the COPD subjects in terms of age, body mass index (BMI), tobacco smoking (in pack-years) and gender. These subjects with normal spirometry made up two additional subgroups, namely, dairy farmers without COPD (DF-controls) and non-dairy farmers without COPD (NF-controls).

Subjects from these four subgroups underwent a characterization visit at the University Hospital of Besançon, during 
which examinations were performed and questionnaires were administered, as described in detail elsewhere. ${ }^{21}$ The distribution of the study population is detailed in Figure 1.

Ethical approval was received from the local Ethics Committee (Comité de Protection des Personnes Est; authorization 11/617). All participants were informed of the study procedures, and written consent was obtained from all included subjects.

\section{Questionnaires}

During the characterization visit, several standardized questionnaires were administered to the four participating subgroups.

A medical questionnaire (completed by the physician) collected data on anthropometric and demographic characteristics, symptoms and smoking history. Each patient was asked about their history of exacerbation, sputum and allergies. Dyspnea was assessed using two scales, namely, the Baseline Dyspnea Index (BDI) and the modified Medical Research Council scale (mMRC). A 6-minute walk test was performed to calculate the BMI, airflow Obstruction, Dyspnea and Exercise capacity (BODE) index. This score combines BMI, $\mathrm{FEV}_{1}, \mathrm{mMRC}$ and 6-minute walk test. ${ }^{24}$ Smoking status was recorded and the number of pack-years was calculated. Subjects who smoked on average less than one cigarette (or cigar or pipe) a day for a year were categorized as never-smokers. If the amount smoked was higher than this value, patients were considered as current smokers. Subjects who had stopped smoking for at least 1 month were considered as former smokers.

Patients completed the self-administered HADS to assess anxiety and depression. The HADS is composed of 14 questions, 7 for the anxiety subscale and 7 for the depression subscale. Each question has four responses rated on a scale of $0-3$, with a maximum score of 21 for each subscale (indicating a high level of distress). For each subscale, a score of 0-7 corresponds to an absence of symptoms of anxiety and/or depression, a score between 8 and 11 corresponds to borderline symptoms of anxiety and/or depression and a score $>11$ corresponds to the certain presence of symptoms of anxiety and/or depression. ${ }^{17,25,26}$

Quality of life was assessed by the St George's Respiratory Questionnaire (SGRQ). The SGRQ is a questionnaire of 50 items designed to measure the quality of life in patients

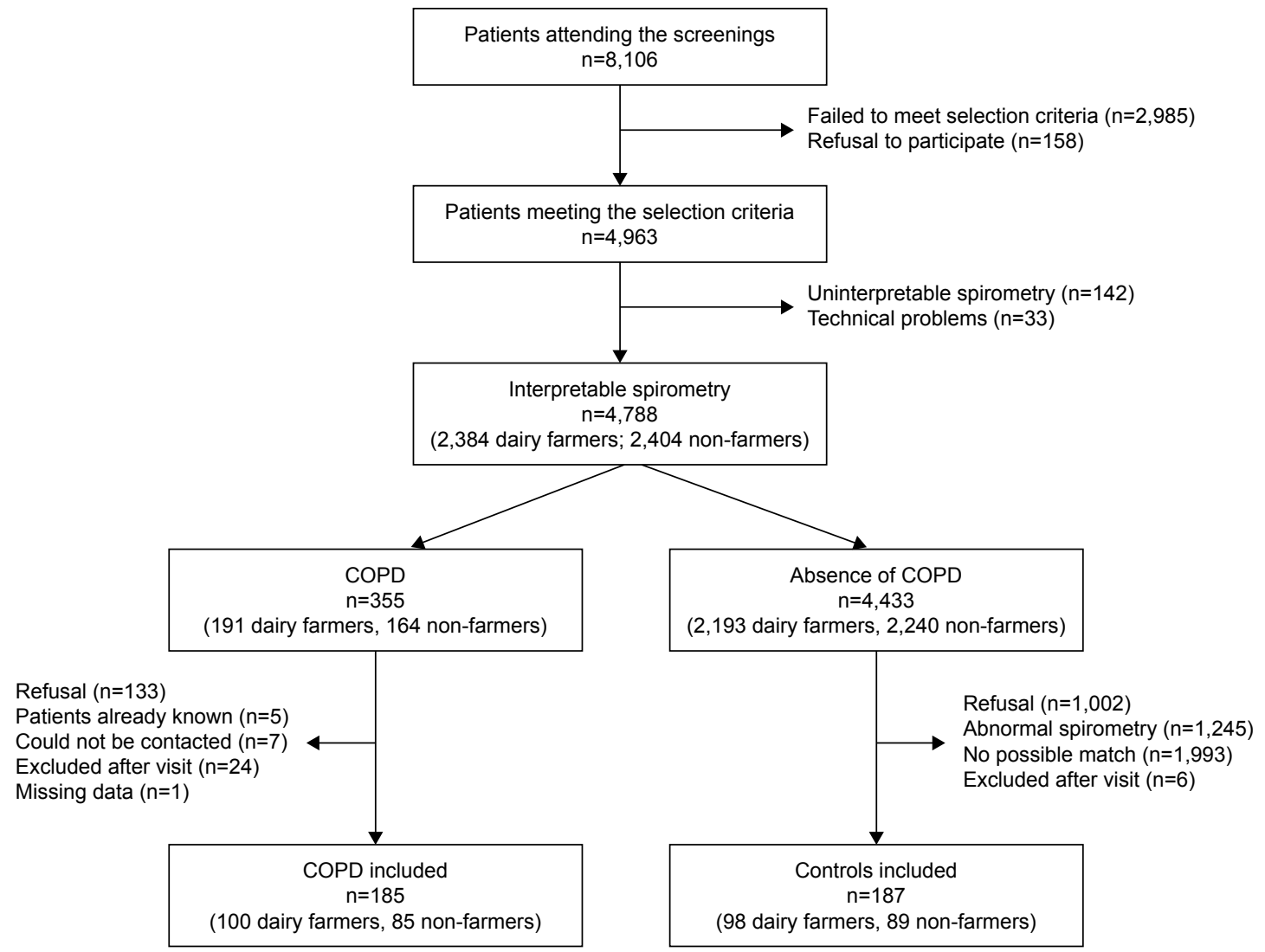

Figure I Flowchart of the population.

Abbreviation: COPD, chronic obstructive pulmonary disease. 
with obstructive lung disease. A high score indicates a significant impairment of quality of life. ${ }^{27}$ It is assumed that a difference of 4 points in the SGRQ is clinically relevant to differentiate groups of subjects. ${ }^{28}$

\section{Statistical analysis}

Data are presented as number (percent) and mean \pm standard deviation for qualitative and quantitative variables, respectively.

Anxiety and depression variables were dichotomized with a cutoff at 8 for absence of anxiety or depression symptoms vs possible/certain presence of anxiety or depression symptoms. ${ }^{17,25,26}$ Hereinafter, these two conditions are designated as absence and presence of anxiety and depression, for simplification.

Characteristics of COPD and control subjects, stratified by professional status (dairy farmers vs non-farmers), were compared using Student's $t$-test and chi-square test for quantitative and qualitative variables, respectively. Characteristics of DF-COPD and NF-COPD subjects were compared using the same methodology.

The prevalence of anxiety and depression was compared in the four groups using the chi-square test. Logistic regressions adjusted for post-bronchodilator $\mathrm{FEV}_{1}$ (\% predicted value) were performed to compare the prevalence of anxiety between dairy farmers and non-farmers. The same methodology was used to compare the prevalence of depression between dairy farmers and non-farmers.

To identify factors associated with anxiety among dairy farmers and non-farmers, bivariate logistic regressions for all candidate factors were performed. Odds ratios (ORs) were presented using forest plots. The same methodology was used to identify factors associated with depression.

A $p$-value $<0.05$ was considered statistically significant. Analyses were performed using SAS software (version 9.3; SAS Institute, Inc., Cary, NC, USA).

\section{Results}

\section{Population characteristics}

Among the 8,106 subjects who underwent screening, 4,963 met the inclusion criteria for the study (61.2\%). In total, 355 patients with COPD (191 dairy farmers and 164 non-farmers) were identified (7.4\% of all subjects with interpretable spirometry) and 4,433 had normal spirometry. A total of 210 COPD patients and 193 non-COPD matched controls agreed to participate in the characterization phase of the study. Thirty patients were excluded, mainly owing to a history of asthma or occupational exposure other than dairy farming (Figure 1). In addition, one DF-COPD patient was not included in this analysis because of missing HADS data. Finally, the DF-COPD, DF-controls, NF-COPD and NF-controls groups comprised 100, 98, 85 and 89 patients, respectively (Figure 1 and Table 1 ).

Table I Population characteristics

\begin{tabular}{|c|c|c|c|c|c|c|c|c|c|c|c|}
\hline \multirow[t]{2}{*}{ Characteristics } & \multicolumn{2}{|l|}{$\begin{array}{l}\text { DF-COPD } \\
(n=100)\end{array}$} & \multicolumn{3}{|l|}{$\begin{array}{l}\text { DF-controls } \\
(n=98)\end{array}$} & \multicolumn{2}{|l|}{$\begin{array}{l}\text { NF-COPD } \\
(n=85)\end{array}$} & \multicolumn{4}{|l|}{$\begin{array}{l}\text { NF-controls } \\
(n=89) \\
\end{array}$} \\
\hline & Mean \pm SD & $\%$ & Mean \pm SD & $\%$ & $p$-value ${ }^{a}$ & Mean \pm SD & $\%$ & Mean \pm SD & $\%$ & $p$-value ${ }^{b}$ & $p$-value ${ }^{c}$ \\
\hline Age (years) & $60.3 \pm 9.1$ & - & $59.3 \pm 8.9$ & & 0.448 & $61.4 \pm 7.6$ & & $60.2 \pm 6.5$ & & 0.240 & 0.342 \\
\hline Men & - & 86 & - & 88 & 0.715 & - & 78 & - & 73 & 0.481 & 0.139 \\
\hline Smoking status & & & & & 0.289 & & & & & 0.313 & $<0.001$ \\
\hline Non-smoker & - & 47 & - & 55 & & - & 8 & - & 14 & & \\
\hline Former smoker & - & 33 & - & 33 & & - & 42 & - & 47 & & \\
\hline Active smoker & - & 20 & - & 12 & & - & 50 & - & 39 & & \\
\hline Number of pack-years & $12.7 \pm 16.8$ & & $8.1 \pm 12.1$ & & 0.028 & $31.4 \pm 23.1$ & & $24.4 \pm 17.8$ & & 0.026 & $<0.001$ \\
\hline FEV, (\% predicted) & $90 \pm 16$ & & $112 \pm 12$ & & $<0.001$ & $84 \pm 17$ & & $115 \pm 13$ & & $<0.001$ & 0.020 \\
\hline GOLD stage & & & & & & & & & & & 0.029 \\
\hline I & - & 75 & - & - & - & - & 60 & - & - & & \\
\hline$\geq 2$ & - & 25 & - & - & - & - & 40 & - & - & & \\
\hline $\mathrm{mMRC}$ & $0.40 \pm 0.55$ & & $0.15 \pm 0.36$ & - & $<0.001$ & $0.6 I \pm 0.77$ & & $0.25 \pm 0.57$ & & $<0.001$ & 0.041 \\
\hline BDI & $10.9 \pm 1.4$ & & $11.5 \pm 1.0$ & - & $<0.001$ & $10.1 \pm 2.1$ & & 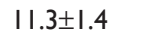 & & $<0.001$ & 0.006 \\
\hline Symptoms ${ }^{d}$ & - & 74 & - & 42 & $<0.001$ & - & 79 & - & 42 & $<0.001$ & 0.420 \\
\hline SGRQ & $14.8 \pm 12.6$ & & $7.5 \pm 7.3$ & & $<0.001$ & $19.2 \pm 14.8$ & & $9.4 \pm 9.1$ & & $<0.001$ & 0.028 \\
\hline BODE & $0.20 \pm 0.55$ & & $0.04 \pm 0.21$ & & 0.012 & $0.42 \pm 0.81$ & & $0.1 I \pm 0.4 I$ & & 0.002 & 0.034 \\
\hline
\end{tabular}

Notes: a Comparison between DF-COPD and DF-controls. ${ }^{\mathrm{b} C}$ Comparison between NF-COPD and NF-controls. ' ${ }^{\mathrm{C}}$ Comparison between DF-COPD and NF-COPD. ${ }^{\mathrm{d} S y m p t o m s: ~}$ presence of at least one symptom among dyspnea, chronic cough and chronic sputum. Dairy farmers with COPD (DF-COPD), dairy farmers without COPD (DF-controls), non-farmers with COPD (NF-COPD), and non-farmers without COPD (NF-controls).

Abbreviations: BDI, Baseline Dyspnea Index; BODE, Body mass index, airflow Obstruction, Dyspnea and Exercise capacity index; COPD, chronic obstructive pulmonary

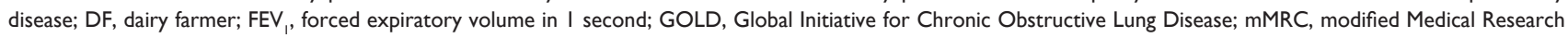
Council scale; NF, non-farmer; SD, standard deviation; SGRQ, St George's Respiratory Questionnaire. 


\section{Anxiety}

$\operatorname{adjOR}(\mathrm{DF}-\mathrm{COPD}$ vs NF-COPD) $=0.92(0.51-1.66)$

adjOR (DF-COPD vs DF-Controls) $=0.72(0.34-1.19)$

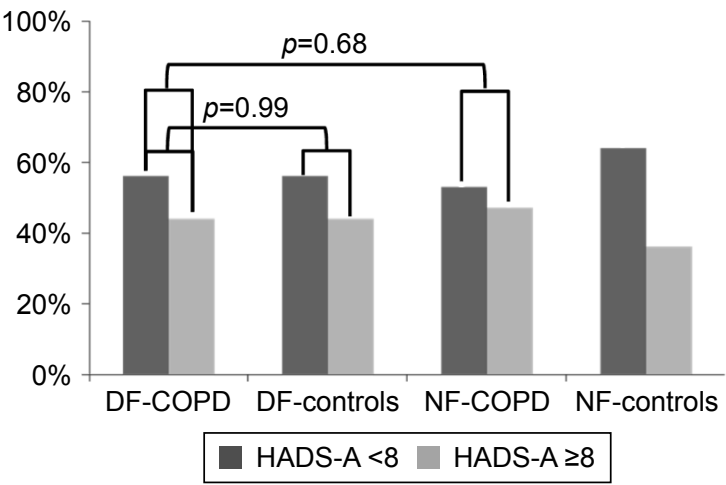

Depression

$\operatorname{adjOR}(D F-C O P D$ vs NF-COPD) $=1.15(0.53-2.52)$

$\operatorname{adjOR}($ DF-COPD vs NF-COPD) $=0.54(0.17-1.71)$ $p=0.73$

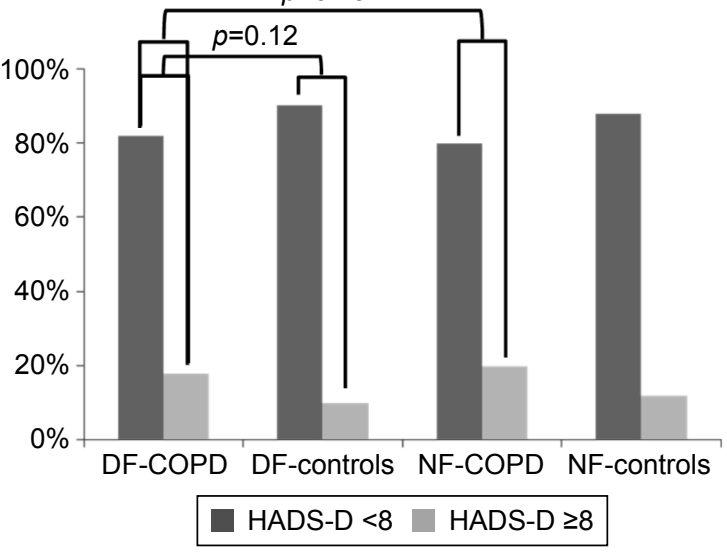

Figure 2 Prevalence of anxiety and depression among dairy farmers with COPD (DF-COPD), dairy farmers without COPD (DF-controls), non-farmers with COPD (NF-COPD) and non-farmers without COPD (NF-controls). ORs are adjusted (adjOR) on FEV, post-bronchodilator.

Abbreviations: COPD, chronic obstructive pulmonary disease; FEV , forced expiratory volume in I second; HADS-A; Hospital Anxiety and Depression Scale - anxiety subscale; HADS-D; Hospital Anxiety and Depression Scale - depression subscale; OR, odds ratio.

The DF-COPD and NF-COPD subgroups were composed mainly of mild COPD with preserved $\mathrm{FEV}_{1}$ (Table 1). The number of current smokers and former smokers was lower among farmers than among non-farmers (Table 1). The proportion of men was higher among farmers than among non-farmers. Dyspnea was more frequent and quality of life scores were lower among COPD patients than among control subjects without COPD (Table 1).

\section{Prevalence of anxiety and depression}

The crude prevalence of anxiety (HADS-anxiety subscale score $\geq 8$, indicating possible/probable symptoms of anxiety) was similar in the four subgroups. Neither COPD nor dairy farming was associated with an increased frequency of anxiety (Figure 2).

Similarly, the prevalence of depression (HADS-depression subscale score $\geq 8$, indicating possible/probable depression) was similar in the four subgroups (Figure 2).

\section{Factors associated with anxiety and depression}

Among farmers, anxiety was associated with current smoking (OR: 2.53 [1.12-5.70], $p=0.03$ ) and with poorer quality of life as measured by the SGRQ score (OR: 1.05 [1.02-1.08], $p=0.003$ ), which is shown in Figure 3. Among non-farmers, anxiety was associated with lower FEV (OR: 0.98 [0.97-0.99], $p=0.03$ ), more severe dyspnea (higher mMRC score [OR: $2.76\{1.62-4.69\}]$ and lower BDI [OR: 0.73 $\{0.61-0.89\}], p<0.001$ for both), female gender (OR: 3.23
[1.58-6.60], $p=0.001$ ), younger age (OR: 0.95 [0.91-0.99], $p=0.03$ ), presence of COPD-related symptoms (OR: 1.98 $[1.05-3.74], p=0.04)$, lower quality of life as evaluated by the SGRQ (OR: 1.06 [1.03-1.08], $p<0.001$ ) and higher BODE score (OR: 1.72 [1.02-2.91], $p=0.04$ ).

Depression among dairy farmers was associated with lower FEV 1 (OR: 0.96 [0.94-0.98], $p<0.001$ ), more severe COPD grades, that is, grade 2 or more (OR: 4.13 [1.41-12.07], $p=0.003$ ), more severe dyspnea on the mMRC scale (OR: 2.23 [1.07-4.65], $p=0.03)$, lower quality of life as measured by the SGRQ score (OR: 1.08 [1.04-1.12], $p<0.001)$ and current smoking (OR: 3.37 [1.29-8.81], $p<0.01$ ), as shown in Figure 4. Among non-farmers, depression was associated with

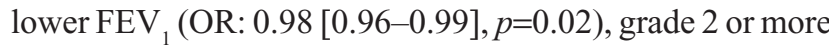
COPD (OR: 3.59 [1.18-10.93], $p=0.02$ ), more severe dyspnea using either the mMRC scale (OR: 2.94 [1.69-5.12], $p<0.001$ ) or the BDI score (OR: 0.68 [0.56-0.84], $p=0.006$ ), presence of symptoms (OR: 3.63 [1.31-10.09], $p=0.009$ ), female gender (OR: 3.35 [1.44-7.80], $p=0.004$ ), poorer quality of life (OR: 1.06 [1.03-1.09], $p=0.001$ ) and a higher BODE score (OR: 2.00 [1.19-3.39], $p=0.01$ ).

\section{Discussion}

This study performed in dairy farmers and in subjects with no occupational exposure in the French Franche-Comté region shows that 1) the prevalence of anxiety and depression as assessed by the HADS was similar in dairy farmers and non-farmers, whether with or without COPD; 2) some COPD-associated features, such as COPD severity, 


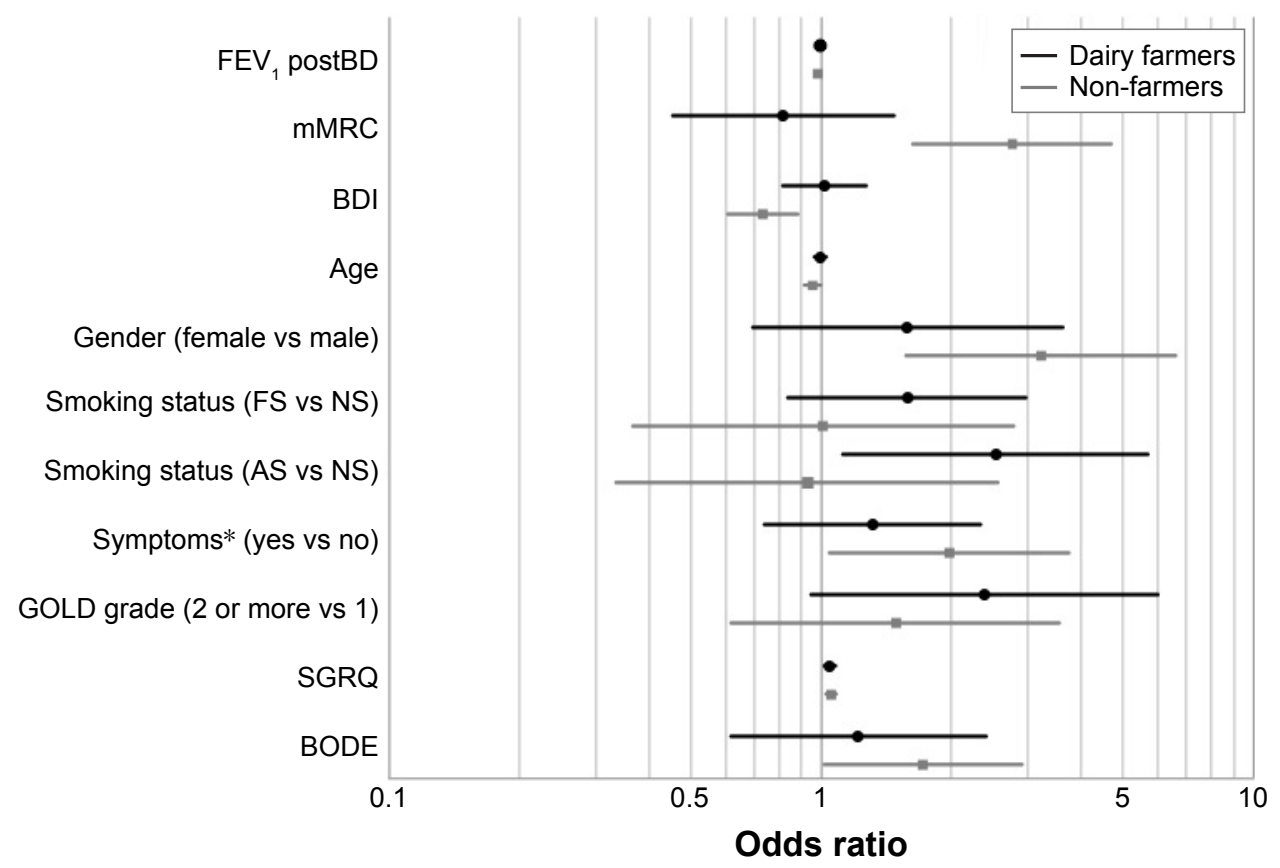

Figure 3 Factors associated with anxiety among dairy farmers and non-farmers.

Note: *Symptoms: presence of at least one symptom among dyspnea, chronic cough and chronic sputum.

Abbreviations: AS, active smoker; BDI, Baseline Dyspnea Index; BODE, Body mass index, airflow Obstruction, Dyspnea and Exercise capacity index; FEV, post-BD, forced expiratory volume in I second post-bronchodilator; FS, former smoker; GOLD, Global Initiative for Chronic Obstructive Lung Disease; mMRC, modified Medical Research Council scale; NS, non-smoker; SGRQ, St George's Respiratory Questionnaire.

dyspnea and quality of life, were associated with depression in dairy farmers as well as in subjects with no occupational exposure; and 3) there was no relationship between anxiety and COPD-associated features among dairy farmers.
Several studies have shown that the farming population is at higher risk of anxiety, depression and even suicide than the general population. In a study conducted in the USA, male farmers, fishermen and foresters had the highest age-adjusted

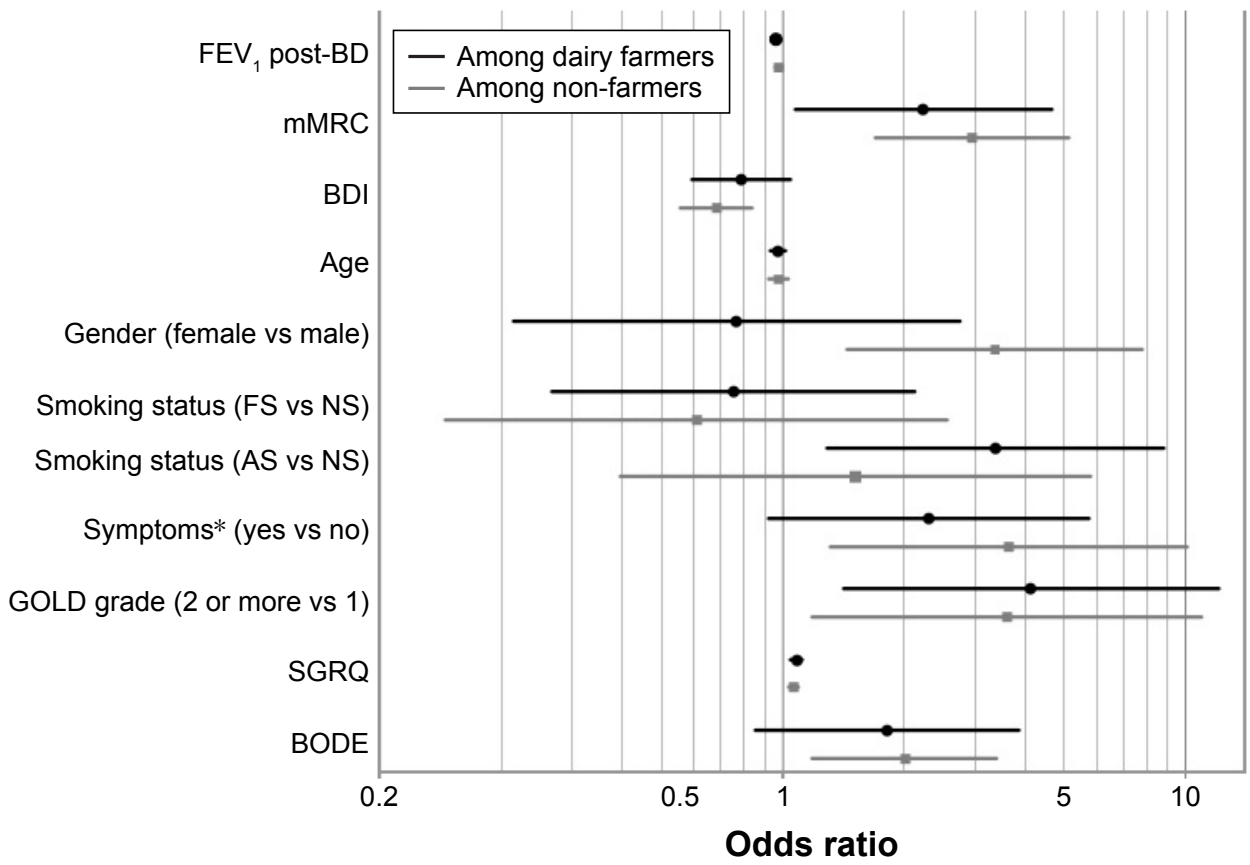

Figure 4 Factors associated with depression among dairy farmers and non-farmers.

Note: *Symptoms: presence of at least one symptom among dyspnea, chronic cough and chronic sputum.

Abbreviations: AS, active smoker; BDI, Baseline Dyspnea Index; BODE, Body mass index, airflow Obstruction, Dyspnea and Exercise capacity index; FEV , post-BD, forced expiratory volume in I second post-bronchodilator; FS, former smoker; GOLD, Global Initiative for Chronic Obstructive Lung Disease; mMRC, modified Medical Research Council scale; NS, non-smoker; SGRQ, St George's Respiratory Questionnaire. 
suicide rates (476 per 100,000), well above those of non-farmers (113 per $100,000, p<0.05) .{ }^{29}$ In another study using the HADS, male farmers $(n=1,100)$ had a higher prevalence of depression than non-farming male workers $(n=10,026)$, with an age-adjusted OR of 1.49 (95\% CI: 1.22-1.83). ${ }^{17}$ Nevertheless, in this latter study, the prevalence of anxiety was similar in farmers and non-farmers. ${ }^{17}$ Although our study was not designed to compare anxiety and/or depression between healthy farmers and healthy non-farmers, we did not observe any difference between these two groups. A point of note is that similar prevalences of anxiety and depression were found in our study in dairy farmers with COPD and in non-farmers with COPD ( $p=0.68$ and $p=0.73$ for anxiety and depression, respectively). This may be due to the particular situation of dairy farmers in the Franche-Comté region. They sell their milk to the cheese manufacturing sector, in particular, for the production of the highly reputed Comte cheese, which is safeguarded by a protected designation of origin, guaranteeing a higher selling price for the milk. It may also be related to the design of our study, in which 1) only subjects who agreed to undergo a health checkup were included in the COPD screening program and 2) only half of the subjects who had COPD detected by screening agreed to attend the hospital visit for characterization. It has previously been reported that among all subjects who are invited for the health checkups organized by the French agricultural health insurance system (MSA), those who attend these checkups and those who do not have different health characteristics. ${ }^{30}$ It is, therefore, possible that our population was not representative of the whole population of dairy farmers.

Some data have previously highlighted the association between COPD and anxiety and/or depression. More than 15 years ago, a study reported that among 79 patients with grade 2 or more COPD, 50\% had anxiety and 28\% had depression as assessed by a HADS score $\geq 8 .{ }^{25}$ More recently, a study of 302 COPD patients (106 in grade 1 and 196 in grade 2 or more) showed that $53 \%$ had anxiety and $45 \%$ had depression, also assessed by a HADS score $\geq 8 .{ }^{26}$ In this study, anxiety and depression were not limited to the most severe forms of COPD, since $34 \%$ of patients with anxiety and $28 \%$ of patients with depression had grade 1 COPD. ${ }^{26}$ Nevertheless, large differences in the prevalence of anxiety and depression in COPD have been observed from one study to another, ranging from $10 \%$ to $55 \%$ for anxiety and from $15 \%$ to $36 \%$ for depression. ${ }^{7,8}$ In our study, we failed to find any difference in anxiety and/or depression prevalence between COPD patients detected by screening the majority being Global Initiative for Chronic Obstructive Lung Disease grade 1 - and selected controls matched for age, gender and tobacco habits. Again, this finding might be due to a selection bias secondary to the study design. The discrepancy with the literature could also be due to the choice of the threshold value of 8 for the HADS. In our population, most subjects with a score $>8$ had a score $<11$, placing them in the borderline category, and only a minority had a score $>11$ (probable anxiety and/or depression). Nonetheless, a robust literature review revealed an optimal balance between sensitivity and specificity for a threshold of 8 , for both anxiety and depression. ${ }^{31}$

In our population, anxiety and depression were associated with higher SGRQ scores, reflecting poorer quality of life. The mean difference in SGRQ between patients with vs without anxiety was 5-8 points, and the average difference between depressed and non-depressed patients was more than 10 points. These differences are well above the 4-point threshold defining the minimum clinically important difference. For a similar level of anxiety and depression, the impact on the quality of life measured by the SGRQ tended to be greater among non-farmers than among farmers, despite similar mean $\mathrm{FEV}_{1}$ values in both groups. In addition, anxiety and depression were associated with more severe dyspnea scores among non-farmers only. These results are consistent with studies conducted in the general population, which observed a link between intensity of depression and severity of dyspnea. ${ }^{32,33}$ A point of note is that this association suggests that there is an overlap between symptoms of anxiety and depression on the one hand, and symptoms of COPD on the other hand; this overlap may explain at least in part the association observed in the study. Nevertheless, this result also suggests that among farmers, anxiety and depression are associated with factors other than dyspnea, which may not have been explored in our study.

It seems difficult to characterize anxiety and depression by a single score. It might have been appropriate to use other scores in addition to the HADS, such as the Beck Depression Inventory, Beck Anxiety Inventory and State-Trait Anxiety Inventory. ${ }^{34,35}$ A diagnostic questionnaire, such as the Mini-International Neuropsychiatric Interview or the Composite International Diagnostic Interview questionnaire, could have been administered to our positive cases to confirm the presence of anxiety and/or depression. ${ }^{36,37}$ Finally, a clinical evaluation of anxiety and depression could also have been performed because it can lead to results differing from those of the HADS. For example, in our population, being a woman was associated with the level of anxiety and depression only among non-farmers. In general, the prevalence, incidence and morbidity of depression are higher among women than among men, as early as in their 
teenage years. ${ }^{38}$ Nevertheless, several studies have reported that the depression component of the HADS score was higher in men than in women. ${ }^{39}$ This finding raises questions about the gender-specific validity of the HADS questionnaire. However, it also reinforces the results observed in our population of non-farmers regarding the link between anxiety and/or depression and female gender.

In conclusion, we have shown that dairy farmers with COPD have prevalences of anxiety and depression that are similar to those of dairy farmers without COPD. In accordance with previous reports, we also found that depression was associated with some COPD-related features, such as COPD severity, dyspnea and quality of life, and that this association was similar in dairy farmers and in subjects with no occupational exposure. In contrast, no association between anxiety and COPD-related features was found in our population of dairy farmers. In view of the particular situation of dairy farmers from Franche-Comté in terms of milk selling price, the observation that dairy farming is not associated with increased risk of anxiety and/or depression needs additional studies with other populations.

\section{Acknowledgments}

The authors thank Stéphane Jouneau (Service de Pneumologie, CHU de Rennes, Rennes, France), Henri Simon (Mutualité Sociale Agricole, Besançon, France) and Martial Botebol (FeMaSaC, Besançon, France) for their intellectual contribution.

This study was supported by Novartis Pharma, Mutualité Sociale Agricole, Fédération des Maisons de Santé Comtoises, Don du Souffle and Association Santé Éducation et Prévention sur les Territoires Franche-Comté Bourgogne.

\section{Availability of data and material}

The data that support the findings of this study are available from the corresponding author.

\section{Disclosure}

The authors report no conflicts of interest in this work.

\section{References}

1. Vestbo J, Hurd SS, Agusti AG, et al. Global strategy for the diagnosis, management, and prevention of chronic obstructive pulmonary disease: GOLD executive summary. Am J Respir Crit Care Med. 2013;187(4): 347-365.

2. Monteagudo M, Rodriguez-Blanco T, Llagostera M, et al. Factors associated with changes in quality of life of COPD patients: a prospective study in primary care. Respir Med. 2013;107(10):1589-1597.

3. Jones PW, Brusselle G, Dal Negro RW, et al. Health-related quality of life in patients by COPD severity within primary care in Europe. Respir Med. 2011;105(1):57-66.
4. Pasquale MK, Sun SX, Song F, Hartnett HJ, Stemkowski SA. Impact of exacerbations on health care cost and resource utilization in chronic obstructive pulmonary disease patients with chronic bronchitis from a predominantly Medicare population. Int J Chron Obstruct Pulmon Dis. 2012;7:757-764.

5. Laforest L, Roche N, Devouassoux G, et al. Frequency of comorbidities in chronic obstructive pulmonary disease, and impact on all-cause mortality: a population-based cohort study. Respir Med. 2016;117:33-39.

6. van den Bemt L, Schermer T, Bor H, et al. The risk for depression comorbidity in patients with COPD. Chest. 2009;135(1):108-114.

7. Matte DL, Pizzichini MM, Hoepers AT, et al. Prevalence of depression in COPD: A systematic review and meta-analysis of controlled studies. Respir Med. 2016;117:154-161.

8. Willgoss TG, Yohannes AM. Anxiety disorders in patients with COPD: a systematic review. Respir Care. 2013;58(5):858-866.

9. Maurer J, Rebbapragada V, Borson S, et al; ACCP Workshop Panel on Anxiety and Depression in COPD. Anxiety and depression in COPD: current understanding, unanswered questions, and research needs. Chest. 2008;134(4 Suppl):43S-56S.

10. Schneider C, Jick SS, Bothner U, Meier CR. COPD and the risk of depression. Chest. 2010;137(2):341-347.

11. Atlantis E, Fahey P, Cochrane B, Smith S. Bidirectional associations between clinically relevant depression or anxiety and COPD: a systematic review and meta-analysis. Chest. 2013;144(3):766-777.

12. Ryu JY, Sunwoo YE, Lee SY, et al. Chronic obstructive pulmonary disease (COPD) and vapors, gases, dusts, or fumes (VGDF): a metaanalysis. COPD. 2015;12(4):374-380.

13. Alif SM, Dharmage SC, Bowatte G, et al. Occupational exposure and risk of chronic obstructive pulmonary disease: a systematic review and meta-analysis. Expert Rev Respir Med. 2016;10(8):861-872.

14. Marescaux A, Degano B, Soumagne T, Thaon I, Laplante JJ, Dalphin JC. Impact of farm modernity on the prevalence of chronic obstructive pulmonary disease in dairy farmers. Occup Environ Med. 2016; 73(2):127-133.

15. Guillien A, Puyraveau M, Soumagne T, et al. Prevalence and risk factors for COPD in farmers: a cross-sectional controlled study. Eur Respir J. 2016;47(1):95-103.

16. Gregoire A. The mental health of farmers. Occup Med (Lond). 2002; 52(8):471-476.

17. Torske MO, Hilt B, Glasscock D, Lundqvist P, Krokstad S. Anxiety and depression symptoms among farmers: The HUNT Study, Norway. J Agromedicine. 2016;21(1):24-33.

18. Hounsome B, Edwards RT, Hounsome N, Edwards-Jones G. Psychological morbidity of farmers and non-farming population: results from a UK survey. Community Ment Health J. 2012;48(4):503-510.

19. Fraser CE, Smith KB, Judd F, Humphreys JS, Fragar LJ, Henderson A. Farming and mental health problems and mental illness. Int $J$ Soc Psychiatry. 2005;51(4):340-349.

20. Lunner Kolstrup C, Kallioniemi M, Lundqvist P, Kymalainen HR, Stallones L, Brumby S. International perspectives on psychosocial working conditions, mental health, and stress of dairy farm operators. J Agromedicine. 2013;18(3):244-255.

21. Degano B, Bouhaddi M, Laplante JJ, et al. BPCO des producteurs laitiers: dépistage, caractérisation et constitution d'une cohorte. Étude BALISTIC [COPD in dairy farmers: Screening, characterization and constitution of a cohort. The BALISTIC study]. Rev Mal Respir. 2012;29(9):1149-1156. French.

22. Miller MR, Hankinson J, Brusasco V, et al; ATS/ERS Task Force. Standardisation of spirometry. Eur Respir J. 2005;26(2):319-338.

23. Quanjer PH, Tammeling GJ, Cotes JE, Pedersen OF, Peslin R, Yernault JC. Lung volumes and forced ventilatory flows. Report Working Party Standardization of Lung Function Tests, European Community for Steel and Coal. Official Statement of the European Respiratory Society. Eur Respir J Suppl. 1993;16:5-40.

24. Celli BR, Cote CG, Marin JM, et al. The body-mass index, airflow obstruction, dyspnea, and exercise capacity index in chronic obstructive pulmonary disease. N Engl J Med. 2004;350(10):1005-1012. 
25. Dowson C, Laing R, Barraclough R, et al. The use of the Hospital Anxiety and Depression Scale (HADS) in patients with chronic obstructive pulmonary disease: a pilot study. N Z Med J. 2001;114(1141):447-449.

26. Jácome C, Figueiredo D, Gabriel R, Cruz J, Marques A. Predicting anxiety and depression among family carers of people with chronic obstructive pulmonary disease. Int Psychogeriatr. 2014;26(7):1191-1199.

27. Weatherall M, Marsh S, Shirtcliffe P, Williams M, Travers J, Beasley R. Quality of life measured by the St George's Respiratory Questionnaire and spirometry. Eur Respir J. 2009;33(5):1025-1030.

28. Jones PW. St George's Respiratory Questionnaire: MCID. COPD 2005;2(1):75-79.

29. Stallones L, Doenges T, Dik BJ, Valley MA. Occupation and suicide: Colorado, 2004-2006. Am J Ind Med. 2013;56(11):1290-1295.

30. Pelc A, Danguy V, Gosselin S, Vallée C. Les invités aux instants sante en 2011: profil de consommation de soins des participants et des non participants [Health check up invited people in 2011: healthcare profile of participants and non participants]. 2013. Available from: http://www. msa.fr/lfr/documents/98830/9488297/Les+invit\%C3\%A9s+aux+Insta nts+Sant\%C3\%A9 en+2011.pdf. Accessed November 28, 2017.

31. Bjelland I, Dahl AA, Haug TT, Neckelmann D. The validity of the hospital anxiety and depression scale. An updated literature review. J Psychosom Res. 2002;52(2):69-77.

32. Neuman A, Gunnbjornsdottir M, Tunsater A, et al. Dyspnea in relation to symptoms of anxiety and depression: a prospective population study. Respir Med. 2006;100(10):1843-1849.
33. Sharma P, Morris NR, Adams L. Effect of experimental modulation of mood on perception of exertional dyspnea in healthy subjects. J Appl Physiol (1985). 2016;120(2):114-120.

34. Doyle T, Palmer S, Johnson J, et al. Association of anxiety and depression with pulmonary-specific symptoms in chronic obstructive pulmonary disease. Int J Psychiatry Med. 2013;45(2):189-202.

35. Phan T, Carter O, Adams C, et al. Discriminant validity of the hospital anxiety and depression scale, beck depression inventory (II) and beck anxiety inventory to confirmed clinical diagnosis of depression and anxiety in patients with chronic obstructive pulmonary disease. Chron Respir Dis. 2016;13(3):220-228.

36. Sheehan DV, Lecrubier Y, Sheehan KH, et al. The Mini-International Neuropsychiatric Interview (M.I.N.I.): the development and validation of a structured diagnostic psychiatric interview for DSM-IV and ICD-10. J Clin Psychiatry. 1998;59(Suppl 20):22-33; quiz 34-57.

37. Kessler RC, Ustun TB. The World Mental Health (WMH) Survey Initiative Version of the World Health Organization (WHO) Composite International Diagnostic Interview (CIDI). Int J Methods Psychiatr Res. 2004;13(2):93-121.

38. Faravelli C, Alessandra Scarpato M, Castellini G, Lo Sauro C. Gender differences in depression and anxiety: the role of age. Psychiatry Res. 2013;210(3):1301-1303.

39. Nortvedt MW, Riise T, Sanne B. Are men more depressed than women in Norway? validity of the hospital anxiety and depression scale. J Psychosom Res. 2006;60(2):195-198.
International Journal of COPD

\section{Publish your work in this journal}

The International Journal of COPD is an international, peer-reviewed journal of therapeutics and pharmacology focusing on concise rapid reporting of clinical studies and reviews in COPD. Special focus is given to the pathophysiological processes underlying the disease, intervention programs, patient focused education, and self management protocols.

\section{Dovepress}

This journal is indexed on PubMed Central, MedLine and CAS. The manuscript management system is completely online and includes a very quick and fair peer-review system, which is all easy to use. Visit http://www.dovepress.com/testimonials.php to read real quotes from published authors. 